Re-viewing routines through a Pragmatist lens

\author{
Barbara Simpson \\ Strathclyde Business School \\ barbara.simpson@strath.ac.uk
}

and

Philippe Lorino

ESSEC Business School

lorino@essec.fr

Accepted for Publication in

Perspectives on Process Organization Studies, Volume 6

Forthcoming March 2016 


\section{Re-viewing routines through a Pragmatist lens}

Abstract: The practice-based view that currently dominates the routines literature is based on an ostensiveperformative duality. However, from the perspective of process philosophy, this duality, or at least the manner in which it is applied, presents four key obstacles to a more processual theorization of routines. This chapter offers an alternative approach that builds on Pragmatist philosophy, especially the ideas of John Dewey and George Herbert Mead, which inform a performative rather than a representational approach to understanding ordinary everyday actions. The argument provides an account of the social and temporal situatedness of human conduct in terms of the inter-related processes of habit, inquiry, and conversational trans-actions.

CompCo is a leading global manufacturer of computer hardware. The company's reputation for excellence is grounded in its strict adherence to the principles of Total Quality Management (TQM) and Just in Time (JIT) production. Some years ago, the Board sought to further improve CompCo's competitive position by investing in a cutting edge, completely automated, computer-integrated manufacturing system (CIM) for its printed circuit assemblies factory, which not only provided JIT supplies to CompCo, but also to a number of other computer assembly factories across Europe. CIM is a manufacturing concept that aims to eliminate human error and to enhance productivity by fully automating factory production processes. Depending entirely on real-time closed-loop feedback from automatic sensors and computerized monitoring to control production, CIM has been mythologized as the intelligent 'lights-out' factory that needs no human presence other than a Controller who remotely monitors (rather than controls) the manufacturing processes. 
CIM was implemented at CompCo using an "intelligent" software system in which links between the physical (automated workstations and belt conveyors) and software "layers" of the CIM were facilitated by means of bar-codes. All the components necessary for any scheduled product were picked up and loaded by robots into bar-coded plastic trays. Automated belt conveyors connected a central dispatching station with the various workstations where robotic systems used these components to assemble the required products. Because of the complexity of CompCo's product range and production processes, the prototype CIM initially retained a few manually operated workstations. This human presence was tolerated as a temporary aberration that would be replaced by full automation within a matter of months. One day during this interim period, the whole system stopped working for no apparent reason; carefully planned production routines were thrown into complete disarray. It took the combined efforts of designers, engineers, computer scientists, and technicians over several (very costly) days to discover the problem. A rogue plastic components tray had introduced an unexpected bar code that the intelligent factory could not interpret, and another plastic tray with a monitored bar-code had altogether vanished.

These events were experienced by one of us (Philippe) some 20 years ago, while he was working as a management controller at CompCo. He was fully engaged as a participant in this episode, contributing to the analysis and feedback processes that ensued. Over the following five years, he continued to discuss the episode with others who had been involved in this situation, then later he extended his exploration with academic colleagues. To us, it is a story that invites questions about often invisible and taken-for-granted assumptions regarding 
human action at the human-machine interface, and in particular about the situated actions that emerge through social interactions. There is an element of unanticipated human intervention that must be unraveled if lessons are to be learned from the CompCo experience. How are we to understand what happens when well-planned actions fall apart, and how should we theorize the improvisational actions that inevitably arise in such situations (Suchman, 1987)?

Routines theory has potential to open up some useful insights into the CompCo story. For instance, it might seek to understand how production routines changed while at the same time persisting throughout the introduction of the new CIM system (Howard-Grenville, 2005). It might demonstrate how patterns of action were varied, retained and selected in the evolution of production routines (Pentland et al., 2012). Or it might map the learning processes that accompany this evolving process (Rerup and Feldman, 2011). More generally, a practice-based theorization of routines (Feldman, 2000; Feldman and Pentland, 2003) may be very helpful in understanding how people's actions intervene in the processes of creating, maintaining, disrupting, and changing routines, where these are understood as "repetitive, recognizable patterns of interdependent actions, carried out by multiple actors" (Feldman and Pentland, 2003: 95). This definition not only recognizes human agency in the performation of routines, but it also acknowledges the relationality of social (and material) interactions. What is missing though, is a thorough-going theorization of the temporal dimensions of those situated actions that comprise routines. This is precisely where process theory might very productively intersect with contemporary understandings of routines. 
In this chapter, we pursue this opportunity for theory development firstly by investigating the ontological and epistemological status of routines in organizing processes. Analyzing the limits of routines theory, both in its historical behaviorist form (March and Simon, 1993) and in its later practice-based form (Feldman and Pentland, 2003), we uncover four obstacles to a more processual appreciation of human conduct. Next, we propose an alternative theorization inspired by Pragmatist thinking about human action as a continuously emerging social process of meaning-making. Taking human conduct as the motive force for social change, the Pragmatists developed a practical and fundamentally processual understanding of those movements that shape, and are shaped by our everyday experiences of living. We focus particularly on the ideas of John Dewey and George Herbert Mead, both of whom are already known to the routines community (Cohen, 2007; Dionysiou and Tsoukas, 2013; Winter, 2013), but here we go further by exploring three specific dimensions (habit, inquiry, and conversational trans-action) in their Pragmatist theory of creative action (Joas, 1996). As we unfold each of these dimensions, we will return to CompCo to illustrate and deepen our practical understandings of the situation. We argue that these three dimensions, taken in combination, offer fresh insights into the relational and temporal dynamics of routines.

\section{A processual critique of routines theory}

Scholarly interest in routines as mechanisms for the accomplishment of organizational work has been growing steadily for the past three decades (Becker, 2004; Parmigiani and HowardGrenville, 2011), but arguably it was the seminal work of March and Simon, first published in 1958, that opened this topic up to organizational researchers. They suggested that the activities associated with problem-solving may be routinized "to the degree that choice has been simplified by the development of a fixed response to defined stimuli" (1993: 163). They 
further recognized that the 'rationality' of the chooser is always bounded by the specifics of both past experience and current situation. Thus for them, a routine is a "response ... that has been developed and learned at some previous time as an appropriate response for a stimulus of this class" (1993: 160). The behaviorist language of stimulus-response is pervasive in March and Simon's argument. It implies that routinized activity is determined by some sort of environmental stimulus, and that the learned response to this stimulus is immediately available without further cognitive intervention. There is a clear causal sequence - first stimulus, then response - so routines are understood as automatically triggered responses to previously experienced stimuli. Problem-solving activities are invoked only by exception, when the available repertoire of routine responses, or performance programs, proves inadequate for a given stimulus. Even in this situation though, March and Simon envisage the execution of procedural plans based on pre-existing procedures for problem-solving.

This stimulus-response model is underpinned by a representational theory of mind. That is, it assumes the classic Cartesian separation of mind and body, which understands thinking as a way of forming cognitive representations of the experienced world, and acting as the execution of already formed representations. This dualistic formulation is, however, a serious point of contention for process theorists, who see it as cutting across the very processes that are of interest, reducing movement to static representations, and thereby failing to account for the relational and temporal dynamics of practical organizational situations (Simpson, 2009). As far back as 1896, Dewey was arguing that the only way to overcome dualisms such as stimulus-response is by not starting from disjointed parts (i.e. stimuli, processing, responses), but by asking how these parts hang together. In his view, it is not that the stimulus sets the organism in motion, but rather the organism, as long as it is alive, is always already 
in motion. Living means moving. Stimulus and response are then each understood as complete acts that are mutually constituting in the processes of living rather than being related in a strictly causal sequence (Burbules, 2004). This re-conceptualization of stimulus and response as an ongoing and dynamic interplay requires an ontological shift away from the substantialist assumptions of a representational idiom, towards the processual assumptions of a performative idiom (Pickering, 1995), which emphasizes way-finding rather than navigation (Chia and Holt, 2009; Suchman, 1987), and novelty emergence rather than predictability of outcomes (Garud et al., 2015).

Perhaps anticipating this critique, March and Simon stressed the subjective and social nature of their subjects' rationality which, far from being a purely physiological reflex, they saw as rooted in social experience. But then the very notion of 'stimulus' becomes problematic. In psychological theories, a stimulus is a mere perceptual phenomenon but, giving the example of customer order management, March and Simon stretched this concept into a much thicker and more complex idea that comes close to the notion of a constructed narrative. Responding to these definitional issues, Feldman and Pentland (2003) re-framed routines as complex systems of action that engage both ostensive and performative aspects. "The ostensive aspect is the ideal or schematic form of a routine. It is the abstract, generalized idea of the routine, or the routine in principle. The performative aspect of the routine consists of specific actions, by specific people, in specific places and times. It is the routine in practice. Both of these aspects are necessary for an organizational routine to exist" (2003: 101). Feldman and Pentland took their inspiration for this re-theorization from their reading of Latour (1986), who contrasted ostensive and performative approaches to the problem of power and its functioning in society. However, he argued that the ostensive and the performative are 
ontologically distinct and incommensurable perspectives that defy efforts of integration into a single unified theory. His definition of the ostensive says "In principle it is possible to discover properties which are typical of life in society and could explain the social link and its evolution, though in practice they might be difficult to detect" (1986: 272), while he defined the performative saying "It is impossible in principle to define the list of properties that would be typical of life in society although in practice it is possible to do so" (1986: 273). Whilst either definition might be adopted to study power, like oil and water, the ostensive and performative cannot be blended together.

Drawing these threads of critique together, we see four key obstacles to a more processual theorization of routines:

Obstacle $1 \quad$ Duality or dualism?

Dualisms are a recognized problem for those theories of action that seek to account for the mutually constituting dynamics of human conduct (Bourdieu, 1990; Giddens, 1984; Joas, 1996). A dualism separates systems of action into discrete entities, each of which is defined in opposition to the other, each therefore being immanent in the other (e.g. mind is that aspect of human experience that is not body, and vice versa). There is thus an underlying commonality (the system of action itself) that allows opposing aspects to be unified in an inclusive theory, but one that necessarily lacks dynamism because it is built out of stable entitative units. Both Giddens and Bourdieu rejected dualistic accounts in favor of the numerical notion of duality which, like Latour's distinction between ostensive and performative definitions, is based on two alternative ways of being in, and knowing about the world. The social worlds in which we live are, of course, whole and continuous; they appear 
to have dual, or plural, natures only because of the limitations of our theoretical (and philosophical) assumptions (Dewey, 1917). There is no possibility of unifying these different natures, at least not at the same level of experience as that which created the duality. Nevertheless, the alternative positions are useful to the extent that they offer radically different insights into human action.

Feldman and Pentland presented their ostensive-performative framing of routines in terms of a duality, which calls for "a new ontology of the underlying phenomenon" (2003: 95). In their description of academic hiring practices in Universities they recognized the paradox inherent in this duality whereby routines are both infinitely variable and yet easily identifiable. However, in proposing a unifying "ostensive-performative ontology" (2003: 103), it is not clear how Feldman and Pentland have tackled the profound ontological differences implied by this duality. Furthermore, they have argued that the ostensive and the performative are "two related parts" (2003: 95), or aspects, of organizational routines. "Each part is necessary, but neither part alone is sufficient to explain (or even describe) the properties of the phenomenon we refer to as 'organizational routines'"' (2003: 95). This seems to suggest a slippage towards the sort of dualistic thinking that would admit both terms, ostensive and performative, as qualifiers of the same underlying concept, namely routines. Latour is very clear that in his view, ostensive theories of society have run their course, so now "we have to shift from an ostensive to a performative definition of society" (Latour, 1986: 272). He does not suggest that this approach can be bolted on to existing, representational notions of practice. His advice would seem to be that more effort is required to better theorize the performative view. 
Obstacle 2 A variance-based theory of learning and organizing

A further implication of dualistic thinking is that it tends to suggest a causal connection between the ostensive and performative aspects of routines such that the performative generates new ideas that transform the ostensive, while the "best practice" and guidance implications of the ostensive encourage modifications in actual performances (Feldman, 2000). This leads to routines being conceived as dual learning systems that engage both ostensive and performative aspects (see Figure 1). The resulting scheme of learning and organizing is variance-based: it is the perceived gap between the ostensive and the performative that motivates ongoing change. Following this logic, a good fit between ostensive and performative aspects would generate a high level of stability, or even resistance to change. "A close match seems likely to indicate and predict stability and perhaps inertia. More disparate matches seem likely to indicate the existence of flexibility or change" (Pentland and Feldman, 2005: 805). Langley (1999) critically contrasted variance-based theories with process theories, arguing that the former are concerned with explaining efficient causal relationships between discrete variables amongst which time ordering is immaterial to the outcomes (Mohr, 1982), while the latter are more appropriate for mapping the probabilistic patterns of time-ordered events. Whereas variance-based theories provide a perspective on planned actions over time, process theories seek to engage in a continuous rethinking and adaptation of action in time. We argue it is this processual perspective that needs to be further developed within the routines literature.

[Insert Figure 1 about here] 
Obstacle 3 The temporal problemAlthough routines are seen as "an important source of flexibility and change" in organizations (Feldman and Pentland, 2003: 94), the literature remains largely mute about their timing and temporality. We can, however, infer a strong logical (cause-effect) and temporal (sequential) link between the ostensive and performative aspects of routines. The ostensive refers to cognitive representations expressed as artefacts such as plans and operating procedures, while the performative is concerned with situated action (Suchman, 1987). The ostensive is assumed to shape and direct performation (or vice versa), implying a sequential theory of time: there are successive phases of thought (modeling, programming, representing) and action (performing, executing). However, in making a separation between thought and action, this theoretical perspective denies the active function of the situation, as a potential source of doubt, beyond minor adjustments: "There are always contextual details that remain open - and that must remain open - for the routine to be carried out" (Feldman and Pentland, 2003: 101).

Whilst representationalism may be a useful fiction to analyze simple situations, it does not work in complex situations (Maturana and Varela, 1992). A more processual approach would situate action in the ongoing and entangled constructions that develop within thinking by/in doing, and doing by/in thinking. There can still be representations, but they do not have the same status as in cognitivist theories. They are just iconic mediations that serve as resources for situated action, but not the (determining) source of that action. As stressed by Weick (1998: 553), "[t]he process that animates these artifacts (structure, control, authority, planning, charters, and standard operating procedures) may well consist of ongoing efforts to rework and reenact them in relation to unanticipated ideas and conditions encountered in the moment". Thus performation, situated in the present moment and circumstances, has an 
emergent and improvisational quality that is often "tacit, taken-for-granted" but nevertheless "part of the infrastructure present in all organizing" (Weick, 1998: 553). The future then appears to actors as an open horizon of possibilities to explore, while the past is a rich, diverse and often contradictory source of inspiration. We suggest, therefore, that routines theory would benefit from the explicit inclusion of more processual understandings of time and temporality.

Obstacle 4 The micro-macro problem

The micro-macro dualism is pervasive and well-recognized as a problem in the social sciences. The issue is, once a system has been separated into discrete levels of analysis, how is it then possible to reassemble the dynamic relationships between these levels? Routines theory faces a paradox: actual situated performances are generally viewed as occurring at the level of the individual, while the routine is an organization-level pattern involving multiple actors. However, "[e]ven an abstract and presumed collective understanding of a routine is not invariable because actors' understanding of a routine will vary with their role and perspective ... [in a way] that makes sense only to the individual in that setting" (Howard-Grenville, 2005: 627). How then are we to move from subjective representations to organizational repetitive schemes? In the routines literature, it is often taken for granted that sociality is based on the commonality of representations: shared mental images, shared artificial / instrumental representations, shared discourses. Differences can then appear as imperfections which can raise difficulties: "If individual orientations differ, we may see contests over the use of routines" (Howard-Grenville, 2005: 627), implying that the normal use of routines is based on individual orientations that do not differ. If we take seriously the notion that all actions and all experiences are socially situated (Howard-Grenville, 2005), 
then they can never be adequately theorized as either purely individual or purely organizational endeavors. Process theorists reject the practice of separating systems into discrete levels of analysis, arguing instead that processes flow across all levels of a system. Their concern is how these processes emerge through practical engagements within concrete situations.

\section{Pragmatism: A processual approach to human social experience}

Pragmatist thinking first arose as a trenchant critique of Descartes' exhortation that, in order to find absolute and universal truths, everything should be subjected to doubt. Charles Sanders Peirce, who is often cited as the father of Pragmatism, rejected the primacy that this Cartesian view affords the individual doubting thinker, isolated from the material and social world. Instead, he anchored his understanding of doubt in the local situated actions of ordinary day-to-day living, through which we discover together practical ways of coping with life's vicissitudes (Locke et al., 2008). Doubt arises when our actions meet with some form of resistance, and it may be resolved by reconstructing the meanings of either the self or the situation, or rather their relationship. This reconstructive activity, which Peirce called Inquiry, is a creative accomplishment that continuously injects the possibilities of novelty and change into the otherwise recurring patterns of social experience (Joas, 1996). The ontological category that underpins this Pragmatist position is process. That is, Pragmatists are more concerned with flow, movement, and the passage of events in time than with variables such as cognitive representations, objects, or the stuff of life more generally. Epistemologically their knowing is accomplished through relational engagement in conversations that transcend the usual dualisms permeating the organizational literature (e.g. stimulusresponse, subject-object, individual-organizational). Furthermore, Pragmatism invites 
methodological innovation as researchers seek to go with the flow, themselves transforming as their research situations unfold.

Of course it is not possible to articulate the whole of the Pragmatist canon in this short chapter. Instead we will focus on three interrelated Pragmatist concepts, habit, inquiry, and conversational trans-action, which we find particularly useful in our re-viewing of routines theory. Although we will now elaborate each of these concepts in turn, in a performative idiom they are intimately engaged together in the unfolding of experience and should not be considered as separate in practice, where habits are continuously involved in lived experience as a resource and mediation of ongoing inquiry, which is achieved collectively through conversational trans-action.

\subsection{Habit}

Within the routines literature, and organization studies more generally, the notion of habit is often presented as an idiosyncratic and purely individual mode of conduct (Hodgson, 1993; Nelson and Winter, 1982) that is contrasted to routines, which are taken to be organizationlevel phenomena. For instance, Becker (1992: 328) defines habit in terms of mechanical behavior that displays "a positive relation between past and current consumption", where the focus is very much on the micro-level. Such habits are stimulus-response reflexes that "require no thought; they are automatic" (Feldman and Pentland, 2003: 97). Pragmatists, however, see habit as much more than a mere tool in efficient and rational decision-making. For them, the defining quality of habit is its dispositional, rather than behavioral, orientation. "[T]he essence of habit is an acquired predisposition to ways or modes of response" (Dewey, 1922 [1957]: 32). It is embedded in social experience as "an attitude of response" (Mead, 
1938: 3). "What habit is depends on when and how it causes us to act" (Peirce, 1878: 257). This dispositional understanding of habit continues to be valued by contemporary writers such as Bourdieu, Elias, and Deleuze (Crossley, 2013).

Dewey put particular effort into re-defining habit as a Pragmatist concept. For him, habits are acquired and continuously modified through experience, but they never fully determine the course of action. They are simultaneously object, resource and outcome of inquiries that are both situated and recursive. A habit is neither a representation of actual action nor the actual performance of an action, but rather it is an acquired resource that mediates between the particular action situation and its organizational, social and temporal contexts. To be precise, it is an inherently social, lively and mutable (Cohen, 2007) organizing resource, a form of social language that makes action recognizable, repeatable and debatable.

At CompCo, we see two different habits in play. Firstly, the rogue plastic components tray appeared in the system due to the actions of a human operator at one of the few remaining manual work stations. The operator noticed that one of the trays on the conveyor belt was damaged - one side was torn and twisted. Fearing that this tray could jam one of the machines, he found some unused trays in a corner of the workshop, he transferred the contents of the broken tray into a new tray, and placed the new tray on the conveyor belt. Understanding the operator's actions is neither straightforward nor obvious. He found himself immersed in an entirely unfamiliar environment populated by many robots but very few of the human beings more usually associated with his experience of manufacturing operations. What he did is surprising in this unfamiliar 'science-fiction' setting because he chose to act on his 
own initiative, rather than asking for help. However, his actions must be understood in the context of existing habits used by skilled workers in that factory.

The operator's actions reflected his well-established habit born of intensive and long term training in TQM, which encourages taking initiative whenever possible to prevent defects and lost production. In engaging a habit from his experience (fixing incidents immediately and locally), he is qualifying the situation as an 'incident' in the ordinary processes of production: there is an established and stabilized production system; there are incidents; a competent operator fixes incidents whenever possible within the existing system. The practical language of TQM is involved in the understanding and the resulting enactment of the situation.

Secondly, the CIM experts engaged different habits drawn from their cultural and professional experience in CIM. They are faced with an inexplicable difficulty when the system shuts down. From their perspective, the problem appears as a technical issue, either at the 'physical level' (sensors, actuators, robot mechanics, communication infrastructures, a broken part that has jammed a machine, an electrical incident, etc.) or at the 'informational level' (a bug in some part of the complex software and telecommunication architecture). The engineers use wellestablished habits calling for detailed technical analyses and the resolution of error protocols. In doing so, they qualify the situation as a prototyping issue: this assembly workshop is an experimental unit; there may still be defects and bugs in the design of the system; and they must be fixed. 
The TQM habit engaged by the operator arises as he imagines the potential future situation of a machine jammed by the broken tray (temporal context) and seeks to avoid difficulties for downstream operators (social context). The habit also transforms the primary meaning and definition of apparently simple objects, such as plastic trays, which prove much more complex and polysemous than at first glance. Should the plastic tray be considered a physical object characterized as broken or not broken, or is it rather an informational object that conveys vital systems information in the form of a bar-code? How this question is answered completely changes the way actors look at and engage with the object.

Habits translate diffusely teleological social motives into immediate actions. They translate mediating 'whys' into detailed and specific 'hows'. "As soon as we have projected [an end], we must begin to work backward in thought. We must change what is to be done into a how, the means whereby. The end thus reappears as a series of 'what nexts,' and the what next of chief importance is the one nearest the present state of the one acting ... Now the thing which is closest to us, the means within our power, is a habit" (Dewey 1922/2002: 36-37). In CompCo, distinct habits translate distinct ends into distinct immediate actions. Running technical diagnostics is a 'how' that translates the 'why': "we must debug an innovative production technology", while replacing the broken tray is a 'how' translating the 'why': "we should fix production incidents".

Habits must be reassessed in each present moment, even in apparently simple situations. At what point should a broken plastic tray be considered a prototyping event instead of an 
ordinary production incident? The intelligence of the situation must be built continuously; it is not an automatic, Pavlovian reflex (Dewey and Bentley, 1949/2008). Habit transforms a singular act performed here and now into a socially meaningful gesture. Therefore, crucially, habit involves ongoing judgment so it cannot be equivalent to mindless repetition. "We must protest against the tendency in psychological literature to limit [habit's] meaning to repetition. It assumes from the start the identity of habit with routine. Repetition is in no sense the essence of habit. Tendency to repeat acts is an incident of many habits but not of all. The essence of habit is an acquired predisposition to ways or modes of response, not to particular acts" (Dewey, 1922 [1957]: 41-42).

\subsection{Inquiry}

'Inquiry' is the term Pragmatists use to describe the process in which habits are mobilized and continuously adapted to new and emerging 'what nexts' (Lorino et al., 2011). It is an evolving and transformational process in which selves and situations are mutually engaged and always in-the-making (Elkjaer and Simpson, 2011). Dewey (1938/1986) defined inquiry very specifically as the process that transforms an indeterminate, or doubtful situation into one that is sufficiently unified that a coherent course of action can be anticipated. However, inquiry is not necessarily visible and neither does it always involve a perceptible rupture in habits.

\footnotetext{
"Some forms of common sense inquiries, which aim at determining what is to be done in some practical predicament, are neither exceptional nor infrequent. For the stock and staple of common sense inquiries and judgments are of this sort. The deliberations of daily life concern in largest measure questions of what to
} 
make or to do. Every art and every profession is faced with constantly recurring problems of this sort ... Farmer, mechanic, painter, musician, writer, doctor, lawyer, merchant, captain of industry, administrator or manager, has constantly to inquire what is better to do next." (Dewey, 1938/1986: 162-63).

Neither are the mechanisms of living reducible to "unintelligent automatism" (Dewey, 1922 [1957]: 70). Human action involves both habit and inquiry: habit-based inquiries develop inquiry-based habits, and vice versa. Retrospectively the process of action may appear as the implementation of some pre-determined plan, but in the present the possibilities for action are manifold, the future is open, and even when uncertainty seems very low, options for action are still contingent.

The CompCo story illustrates two distinct inquiry processes in relation to the breakdown of the CIM system. Firstly, the human operator was confronted with a problem - a broken plastic tray, which he assumed could cause a jam in the production system. At that point, several options were available to him - he might have pressed the emergency stop and brought the whole system to an immediate halt until a maintenance technician could be located; he might have called a member of the design team for advice; or he might have simply turned a blind eye to what he perceived to be a minor problem. In the event, he chose to use his own initiative, something that is very much encouraged in a TQM culture, replacing the broken tray on the conveyor belt. In choosing this action, he was responding to the justified expectations of the company, his peers, and the general TQM orientation towards 'doing a good job'. He interpreted the problematic situation as an 
ordinary production incident, which then allowed him to move quickly to find a solution. In particular, since he was able to find a new tray, he assumed he had solved the problem immediately and locally, remaining the only actor involved in the inquiry. He was not aware of the function of the bar-coding of the plastic components trays, so when the system broke down, it never occurred to him that his actions may have been the cause. As far as he was concerned, his actions had ensured the continuity of the process. He had translated a 'why' into a 'how' through a quick, albeit barely visible inquiry.

Secondly, the inquiry that was triggered for the CIM experts when the prototype production system unaccountably stopped working, was quite visible and formally organized. It started from an implicit characterization of the problematic situation as a technical defect of the new production unit. This was a critical step, which required them to find a hypothetical explanation, which in turn defined what actors should be involved as inquirers (i.e. designers and engineers). There is (or should be) no opportunity for human error to affect the operation of a CIM system, so they looked for a breakdown in either the technical hardware or in the complex software that operates the system. Although the experts understood that a few human operators were still engaged in the process, these people were regarded as 'honorary robots' whose habits of action were all supposed to be preprogrammed and predictable. Eventually they discovered that one of the barcoded trays did not match any planned order in the production schedule, and further that one other tray that was part of the scheduled production had disappeared, and could not be located by any of the multiple sensors. How could 
the designers have anticipated that a plastic tray could vanish, and that an unknown plastic tray could burst in from nowhere?

Inquiry does not start from a structured problem that needs solving. Rather, the first critical phase of inquiry entails the transformation of a 'felt difficulty' into a problem. "There is nothing intellectual or cognitive in the existence of such situations, although they are the necessary condition of cognitive operations or inquiry. In themselves they are precognitive. The first result of evocation of inquiry is that the situation is taken, adjudged, to be problematic ... without a problem, there is blind groping in the dark. The way in which the problem is conceived decides what specific suggestions are entertained and which are dismissed; what data are selected and which rejected" (Dewey, 1938/1986: 111-112), what actors are involved as inquirers and which are left out, and the temporal and spatial scope of the inquiry (Lorino and Tricard, 2012).

At CompCo the indeterminate situation first has no intellectual status, it is just an existential unease: a broken tray on the production line; the assembly line stops working. The first phase of the inquiry, often tacit and rarely verbalized, transforms this existential unease into a structured problem: the broken tray needs to be fixed or replaced, and the bug that stopped the system must be traced.

Once a problem has been constructed, its resolution is sought by engaging abductive, deductive and inductive logics of reasoning (Lorino et al., 2011). Firstly, a plausible hypothesis accounting for the problematic situation is abductively inferred in order to restore intelligibility. Then the hypothesis is translated into empirically testable propositions through 
deductive reasoning. Finally, induction develops an empirical protocol to test the propositions (Peirce, 1998: 441-442). The entire reasoning of inquiry is expressed through active experimentation in which thinking and acting are simultaneous and confluent dynamics. Of course the inquiry steps described here in a sequential way for the purposes of presentation, are inevitably iterative and entangled as they grope for new forms of understanding.

Both inquiries at CompCo were framed by particular, but different problem definitions. Whereas the operator was able to conclude his inquiry quickly by problematizing the situation as a production incident, abducting an efficient solution, and then implementing it, the engineers repeatedly cycled through a series of inquiries because they were unable to abduct a plausible explanation for the system breakdown. Limited by their initial problem definition, they could not imagine any sensible hypotheses. This inquiry was eventually resolved only when the experts expanded their inquiry to include the workstation operators (i.e. 'nonexperts').

\subsection{Conversational trans-action ${ }^{1}$}

The purpose of inquiries and their associated habits is to make sensible the present situation so that practical actions may be discerned. This mobilization of habits and inquiries is situated within social and temporal contexts in what the Pragmatists term 'the act' (Mead, 1938). Arising in the interplay between habit, inquiry and the transformation of organizational or social situations, the act carries within itself "a consoling and supporting consciousness of the whole to which it belongs and which in some sense belongs to it" (Dewey 1922/2002: 331). Situating the whole act within the flow of experience emphasizes both the relational and 
temporal extensiveness of the ongoing experience that structures organizing actions (Simpson, 2014). Evidently agency is in play in this process as choices are made about what and how adjustments are made, but in the Pragmatists' view, this agency is explicitly social rather than individualistic in its expression. It is a form of agency that arises in conversation, and as such, it pervades the social situation (Emirbayer and Mische, 1998; Simpson, 2009).

Mead (1934) did not conceive "conversation" as the mere transmission and reception of vocal utterances, but as an ongoing dynamic of gesture and response, within which situations are continuously reconstructed as conversants come to see what is happening through each other's eyes. It is then the very medium of inquiry. Each gesture in a conversation (whether it be vocal utterance, silence, body language, or mood) is a way of probing the meanings of the situation and of testing out what may happen next. When we gesture, we are not simply sending a message, we are also trying to anticipate the possible responses that our gesturing may engender. By reflexively standing in the other's shoes, we build and maintain sociality so that we can be open to a range of potential responses. Mead understood the conversational flow as a mutually constituting dynamic that engages the meanings of conversants' situations and conversants' selves. Describing this process as a mere interaction between distinct entities is inadequate, whereas Dewey \& Bentley's (1949/2008) term 'trans-action' is intended to indicate that all entities participating in an inquiry are involved on an equal footing and that their very definition and delineation is completely contingent on the progress of the inquiry.

In a conversational situation, this trans-actional approach implies that meaning-making cannot be attributed to any individual, but rather it emerges continuously from the very 
processes of conversing (see also Bakhtin, 1981; Shotter, 2008; Tsoukas, 2009). Any act is always addressed by and addresses other acts, and its meaning depends upon the responses it evokes. Conversation can thus be understood as a continuous process of usually quite subtle, mutual re-orientations. Of course, we carry our habits with us into every conversation, and it is here that these dispositional attitudes are tested and adjusted to bring better, more practically useful understandings of the evolving situation. Ultimately it is selves, and their dispositions to act, that are transformed in conversation, so in Mead's words, "selves exist only in relation to other selves" (1925: 278).

The conversational trans-action is not only relational, but also temporal. In Mead's view (1932), social agency engages both the past and the future as resources that give meaning and direction to actions in the present moment. As we proceed in our living and acting together, we rebuild both past experiences and anticipated futures to continuously re-author our understandings in response to what seems to be going on in the present moment (Simpson, 2014). Presents then, are emergent turning points in the flow of living; they are events that arise whenever something happens. They are the creative confluence of two or more different temporalities. It is in the interweaving of pasts and futures that temporal experience is continuously constituted in the present moment (Hernes et al., 2013; Lorino and Mourey, 2013; Tsoukas and Chia, 2002).

Examining the CompCo story through the lens of conversational trans-actions allows us to step back and take a wider view of the social and temporal dynamics of the situation. We see that the operator and the CIM experts were engaged in quite different temporalities where each had a history of experience that led to 
different anticipated futures. The operator's experience led him to imagine a potential future in which the damaged tray might cause a major problem in the automated production system, and then to resolve this problem using his initiative. The tacit characterization of the situation as an ordinary production incident led to the specific temporal and social configuration of this inquiry. The time horizon of the inquiry was very short - usually production incidents are resolved within a matter of minutes. Potential legitimate inquirers are the normal participants in manufacturing operations: the operator, possibly his/her supervisors and quality controllers, but certainly not system designers.

In contrast, the CIM experts brought deep technical experience to bear on this critical situation. Their tacit characterization of the situation as a system design issue - the debugging of a technical prototype - led to a specific temporal and social configuration over a time horizon spanning the life cycle of the equipment. Legitimate actors were those who would normally be involved with design issues: automation designers and software engineers, but not operators. As a result, the designers' conversational trans-action did not at first involve the operators equally, the operator's decision to replace the tray had not involved the designers.

In a later phase of inquiry, the designers did involve the operators, but only as potential witnesses - had they observed some sign that might be meaningful from a design point of view? In taking this action however, a new conversational configuration was opened up, and the designers discovered the operator's 'communicative gesture' only in the slowly emergent course of the conversation. 
Both the operator and the CIM experts had been functioning within closed and separate social and temporal frames. It was only when conversations began to span these boundaries that new understandings were generated and the problem was eventually identified and remedied.

There is a close link between the conversational form of sociality and temporality (Roth, 2014). The conversational trans-action is not the 'joint' or 'common' production of several participants, but the ongoing re-generation of differences. Conversant A moves the situation in a direction which makes it new for $B$; $B$ responds to $A$ by moving the situation in a direction that makes it new for A ... and so on. The present is fleshed out through this recurrent turntaking as successive turns lead to the gradual emergence of a mediate shape, a kind of discourse in acts (Lorino, 2014). Just as music can never be fully appreciated as a mere sequence of sounds, it is the conversational flow that communicates the overall tone of coordinated action. Hypothetical accounts of the past, invisible expectations of the future, and the gradual emergence of sense in the dialogical dynamics of trans-action are thus temporally linked and interdependent.

At CompCo we can imagine that operators may report no specific observation that could put engineers on a relevant track to find the bug. But equally, one of the operators might have mentioned that the only problem he met was fortunately a problem that he could easily solve by himself, which in turn may have triggered a new abductive phase in the inquiry leading the engineers to a new hypothesis.

\section{Discussion}


This chapter is motivated by a desire to explore what, if anything, a processual view of organizing might add to the currently flourishing literature on organizational routines, especially to the extent that they are seen as "source[s] of flexibility and change" (Feldman and Pentland, 2003: 94). Looking through the lens of process philosophy and theory, we see four key obstacles to a more fluid understanding of how routines are created, maintained, disrupted, and changed. Firstly, we challenge the assumption that ostensive and performative aspects of routines can be united under a single theoretical umbrella. We agree with Latour (1986) that a more productive way forward could be to focus exclusively on developing routines theory within a performative idiom. Of course we acknowledge that this is the road less travelled, but for this very reason it is a path that offers great opportunity to adventurous researchers. Secondly, we point to implicit variance-based assumptions that relate the ostensive and the performative to each other through mutually causal mechanisms. There are two central tenets of variance-based theories that conflict with more processual approaches: (i) they assume the situation being examined is sufficiently stable that any timing differences amongst variables will have no material influence on outcomes; and (ii) they assume that all action is preceded by cognition. By contrast, process theories assume that the situations in which we find ourselves are continuously and endlessly unfolding, and within this flow, thinking and acting reside together as mutually constituting dynamics.

Thirdly, we observe that there is no explicit theorization of temporality in the routines literature. Of course the importance of time as an independent variable as routines unfold from their antecedents to their outcomes, is well recognized (Turner, 2014), and there is also increasing scholarly interest in the temporal orientations of actors in routines (HowardGrenville, 2005), but in these examples, and in the routines literature more generally, time 
remains the abstract time of measuring, dating, and sequencing. It articulates the past as an already known and determined history, while the future is extrapolated from past experience. However, this time-reckoning perspective cannot describe the temporality of the performative flow of living with its characteristics of emergence, unpredictability, and irreversibility. For example, how can we appreciate the temporality of an ordinary conversation that leads to new understandings, the temporality of wine-growers nursing their vineyard through uncertain weather, or the temporality of a football game with its many twists and turns? Whilst routines are undeniably present in each of these examples, they are situated within the flow of temporality rather than simply marching to the external rhythm of time. The inherently processual nature of the performative idiom demands a temporal understanding of the present moment as continuously emergent in the interplay between remembered pasts and imagined futures. Finally, distinctions such as micro-macro, but also individual-organizational, stimulus-response, and stability-change, may function as dualisms that arrest the flow of action, and reduce dynamic situations to static representational forms. Process theory, by contrast, seeks a "practical holism' that eschews the primacy of mentalism, cognitivism or even intentionality in engaging with the day-to-day affairs of the world" (Chia and MacKay, 2007: 228).

To move forward from these critiques, we have proposed an alternative theorization that resonates particularly with the performative idiom. Drawing on Pragmatist thinking, we have developed an argument that frames the social and temporal dimensions of ordinary everyday practice in terms of the mutually embedded and practically inseparable dynamics of habit, inquiry and conversational trans-action. We see the performativity of routines then, as provisionally constituted in the intelligent engagement of inquiry, understood as a 
continuously emergent conversational process in which habitual predispositions to act in certain ways in certain situations are constantly exposed to the experimental logics of abduction, deduction and induction. The existential doubt that initiates an inquiry generates actions, out of which the problem and the solution co-emerge. This is a very different approach from the stimulus-response of March and Simon (1993), where a routine is understood as being triggered by an already fully structured problem. It is holistic experience, rather than reflexes or cognitions, that allows us to connect particular types of situations to arrays of potential options for action. Further, because actors choose amongst their abducted hypotheses in deciding 'what next', their practice may remain stable, it may be radically disruptive and creative, or it may be anything in between. Actions then, are generative to the extent that different histories of experience may coincide to produce alternative anticipated futures. By positioning inquiry alongside conversational trans-action, our performative view of routines is fundamentally temporal as it locates actions in the perpetually unfolding present.

The Pragmatist approach we are advocating is concerned primarily with the flow of experience and processes of mutual transformation. As such, it is both ontologically processual, and epistemologically conversational and relational. These foundational assumptions invite new methodological approaches that engage with underlying processual dynamics, not only through historical analyses, but also by participating directly in the social and temporal presents of practice and engaging with the 'practical holism' of the situation. This requires us to step away from 'levels of analysis' or other dualistic framings, and to immerse ourselves in the confluence of multiple, socially and temporally situated flows of action. It also invites us to carefully re-language the ways we talk about action in order to 
avoid the stasis of representations and keep the dynamics alive in our analytical framings (Mesle, 2008). Whilst this need is well recognized in, for instance, Weick's (1979) entreaty to replace nouns with verbs in our research descriptions, the rush towards the gerund-ing of everything has perhaps now been overdone in the organizational literature. A more subtle relanguaging is called for. We suggest that the confluence of habits, inquiries and conversational trans-actions as defined by the Pragmatists offers just such a re-languaging of familiar ideas in ways that open up new possibilities for analysis and research more generally.

In reviewing the routines literature, we are conscious that the field itself is in a state of dynamic emergence. Step by step, the initial behaviorist account of routines has been deconstructed and replaced by an increased recognition that situated (performative) action is not the same as planned or programmed action. What we are proposing here is yet another step in this process, a step that is timely given recent developments in the field. At the conference that informed this edited volume, Martha Feldman (2014) proposed a new actionbased model of routines built on processes of 'patterning' and 'performing'. We see this as a very exciting move that sits remarkably comfortably with our Pragmatist argument, which allows us to understand patterning and performing, not as contrasting constructs, but as two mutually constituting flows within the same process, that of inquiry. We hope, therefore, that the Pragmatist take on habits, inquiry, and conversational trans-actions will resonate with further developments that advance the performative idiom in routines theory.

Ultimately, the real strength of the Pragmatist approach we have articulated is that it accounts for both the situatedness of actions in terms of the social and relational contexts in which they arise, and also for the continuous reconstruction of pasts and futures in the flow 
of present experience. In doing so, it holds the potential for new theory that integrates the social and the temporal in a thorough-going performative exposition of the means by which the work of organizing is accomplished.

\section{Note}

${ }^{1}$ Here we follow Dewey and Bentley (1949/2008) in hyphenating this word to differentiate its meaning from other common usage, especially in economics and psychoanalysis.

\section{References}

Bakhtin, M.M. (1981). The dialogical imagination: Four essays. Austin: University of Texas Press.

Becker, G.S. (1992). 'Habits, addictions and traditions'. Kyklos, 45: 327-346.

Becker, M.C. (2004). 'Organizational routines: A review of the literature'. Industrial and Corporate Change, 13(4): 643-677.

Bourdieu, P. (1990). The logic of practice. Cambridge, UK: Polity Press.

Burbules, B. (2004). Pragmatism and educational research: Rowman \& Littlefield.

Chia, R. and Holt, R. (2009). Strategy without design: the silent efficacy of indirect action: Cambridge University Press.

Chia, R. and MacKay, B. (2007). 'Post-processual challenges for the emerging strategy-aspractice perspective: Discovering strategy in the logic of practice'. Human Relations, 60(1): $217-242$.

Cohen, M. (2007). 'Reading Dewey: Reflections on the study of routines'. Organization Studies, 28: 773-87.

Crossley, N. (2013). 'Habit and habitus'. Body \& Society, 19(2\&3): 136-161. 
Dewey, J. (1896). 'The Reflex Arc Concept in Psychology'. Psychological Review, 3: 357-370.

Dewey, J. (1917). 'Duality and dualism'. Journal of Philosophy, Psychology and Scientific Methods, 14: 491-493.

Dewey, J. (1922 [1957]). 'Human nature and conduct'. In Middle Works. Boydston, J.A., (ed). Carbondale and Edwardsville: Southern Illinois University Press). 14.

Dewey, J. (1938/1986). 'Logic: The theory of inquiry'. In The later works, 1925-1953. Boydston, J.A., (ed). Carbondale: Southern Illinois University Press). 12.

Dewey, J. and Bentley, A. (Eds) (1949/2008). Knowing and the known. John Dewey, The later works, 1925-1953. Carbondale, IL: Southern Illinois University Press.

Dionysiou, D.D. and Tsoukas, H. (2013). 'Understanding the (Re)Creation of Routines from Within: A Symbolic Interactionist Perspective'. Academy of Management. The Academy of Management Review, 38(2): 181-205.

Elkjaer, B. and Simpson, B. (2011). 'Pragmatism: A lived and living philosophy. What can it offer to contemporary organization theory?'. In Research in the Sociology of Organizations: Special Volume on Philosophy and Organization Theory. Tsoukas, H. and Chia, R., (eds), 55-84. Bingley: Elsevier). Vol 32.

Emirbayer, M. and Mische, A. (1998). 'What is agency? '. American Journal of Sociology, 103(4): 962-1023.

Feldman, M. (2000). 'Organizational routines as a source of continuous change'. Organization Science, 11: 611-629.

Feldman, M. (2014). 'Understanding action in routines'. 6th International Symposium on Process Organization Studies, Rhodes, Greece.

Feldman, M. and Pentland, B. (2003). 'Reconceptualizing organizational routines as a source of flexibility and change'. Administrative Science Quarterly, 48: 94-118. 
Garud, R., Simpson, B., Langley, A. and Tsoukas, H. (2015). "Introduction: How does novelty emerge?'. In Process research in organization studies: the emergence of novelty in organizations. Garud, R., Simpson, B., Langley, A. and Tsoukas, H., (eds), 1-24. Oxford: Oxford University Press.

Giddens, A. (1984). The constitution of society: Outline of the theory of structuration. Cambridge: Polity Press.

Hernes, T., Simpson, B. and Söderlund, J. (2013). 'Managing and temporality'. Scandinavian Journal of Management, 29(1): 1-6.

Hodgson, G.M. (1993). 'Institutional economics: Surveying the "old" and the "new"'. Metroeconomica, 44: 1-28.

Howard-Grenville, J. (2005). 'The persistence of flexible organizational routines: The role of agency and organizational context'. Organization Science, 16(6): 618-636.

Joas, H. (1996). Creativity of action. Chicago: University of Chicago Press.

Langley, A. (1999). 'Strategies for theorizing from process data'. Academy of Management Review, 24(4): 691-710.

Latour, B. (1986). 'The powers of association'. In Power, action and belief. Law, J., (ed). London: Routledge.

Locke, K., Golden-Biddle, K. and Feldman, M.S. (2008). 'Making doubt generative: Rethinking the role of doubt in the research process'. Organization Science, 19(6): 907-918.

Lorino, P. (2014). 'From speech acts to act speeches: Collective activity, a discursive process speaking the language of habits.'. In Perspectives on Process Organization Studies Vol. 4: Language and Communication at Work. Discourse, Narrativity, and Organizing. Cooren, F., Vaara, E., Langley, A. and Tsoukas, H., (eds), 95-124. Oxford: Oxford University Press. 
Lorino, P. and Mourey, D. (2013). 'The Experience of Time in the Inter-Organizing Inquiry: A Present Thickened By Dialog and Situations'. Scandinavian Journal of Management, 29(1): 4862.

Lorino, P. and Tricard, B. (2012). 'The Bakhtinian Theory of Chronotope (Time-Space Frame) Applied to the Organizing Process'. In Perspectives on Process Organization Studies Vol. 2: Constructing Identity in and Around Organizations. Schultz, M., Maguire, S., Langley, A. and Tsoukas, H., (eds), 201-234. Oxford: Oxford University Press.

Lorino, P., Tricard, B. and Clot, Y. (2011). 'Research methods for non-representational approaches to organizational complexity: The dialogical mediated inquiry'. Organization Studies, 32(6): 769-801.

March, J. and Simon, H.A. (1993). Organizations. New York: Wiley.

Maturana, H.R. and Varela, F.J. (1992). The tree of knowledge: The biological roots of human understanding: Boston; London.

Mead, G.H. (1925). 'The genesis of the self and social control'. International Journal of Ethics, 35: 251-77.

Mead, G.H. (1932). The philosophy of the present. Illinois: La Salle.

Mead, G.H. (1934). Mind, self and society. Chicago: University of Chicago Press.

Mead, G.H. (1938). The philosophy of the act. Chicago: University of Chicago Press.

Mesle, C.R. (2008). Process-relational philosophy: An introduction to Alfred North Whitehead. West Conshohocken, PA: Templeton Press.

Mohr, L.B. (1982). Explaining organizational behavior. San Francisco: Jossey-Bass.

Nelson, R.R. and Winter, S.G. (1982). An evolutionary theory of economic change. Cambridge, MA: Belnap Press / Harvard University Press. 
Parmigiani, A. and Howard-Grenville, J. (2011). 'Routines Revisited: Exploring the Capabilities and Practice Perspectives'. The Academy of Management Annals, 5(1): 413-453.

Peirce, C.S. (1878). 'How to make our ideas clear'. In Collected Papers of Charles Sanders Peirce. Hartshorne, C. and Weiss, P., (eds), 248-271. Cambridge, MA: The Belknap Press of Harvard University Press). V.

Peirce, C.S. (1998). The Essential Peirce. Bloomington, IN: Indiana University Press.

Pentland, B. and Feldman, M. (2005). 'Organizational routines as a unit of analysis'. Industrial and Corporate Change, 14(5): 793-815.

Pentland, B., Feldman, M., Becker, M. and Liu, P. (2012). 'Dynamics of organizational routines: A generative model'. Journal of Management Studies, 49(8): 1484-1508.

Pickering, A. (1995). The mangle of practice: Time, agency and science. Chicago and London: University of Chicago Press.

Rerup, C. and Feldman, M. (2011). 'Routines as a source of change in organizational schemata: The role of trial-and-error learning'. Academy of Management Journal, 54(3): 577610.

Roth, W.M. (2014). 'Working Out the Interstitial and Syncopic Nature of the Human Psyche: On the Analysis of Verbal Data'. Integrative Psychological \& Behavioral Science, 48(3): 283-298.

Shotter, J. (2008). 'Dialogism and polyphony in organizational theorizing: Action guiding anticipations and the continuous creation of novelty'. Organization Studies 29(4): 501-524.

Simpson, B. (2009). 'Pragmatism, Mead, and the practice turn'. Organization Studies, 30(12): $1329-1347$. 
Simpson, B. (2014). 'George Herbert Mead'. In Oxford Handbook of Process Philosophy and Organization Studies. Helin, J., Hernes, T., Hjorth, D. and Holt, R., (eds), 272-286. Oxford Oxford University Press.

Suchman, L.A. (1987). Plans and situated actions: The problem of human-machine communication. Cambridge: Cambridge University Press.

Tsoukas, H. (2009). 'A dialogical approach to the creation of new knowledge in organizations'. Organization Science, 20(6): 941-957.

Tsoukas, H. and Chia, R. (2002). 'On organizational becoming: Rethinking organizational change'. Organization Science, 13(5): 567-582.

Turner, S.F. (2014). 'The temporal dimension of routines and their outcomes: Exploring the role of time in the capabilities and practice perspectives'. In Time and work: How time impacts groups, organizations and methodological choices. Shipp, A.J. and Fried, Y., (eds), 115-145. East Sussex: Psychology Press). 2.

Weick, K.E. (1979). Social psychology of organizing. Reading, MA: Addison-Wesley.

Weick, K.E. (1998). 'Improvisation as a Mindset for Organizational Analysis'. Organization Science, 9(5): 543-555.

Winter, S. (2013). 'Habit, deliberation, and action: Strengthening the microfoundations of routines and capabilities'. Academy of Management Perspectives, 27(2): 120-137. 